\title{
An Investigation of the Possible Effects of Favored Contexts in Second Language Vocabulary Acquisition
}

\author{
Omid Rezaei \\ Faculty of Foreign Languages, The university of Isfahan, Isafan, 8174673441, Iran \\ E-mail: omidrezaei.rezaei99@gmail.com \\ Salman Dezhara \\ Faculty of Foreign Languages, The university of Isfahan, Isafan, 8174673441, Iran \\ E-mail: hamangt@hotmail.com
}

Received: May 24, 2011

Accepted: June 16, 2011

Published: December 1, 2011

doi:10.5539/elt.v4n4p97

URL: http://dx.doi.org/10.5539/elt.v4n4p97

\begin{abstract}
It is widely agreed that much second language vocabulary learning occurs while the learner is attentively engaged in the process of reading and interpreting the texts encountered. It is also argued that to understand vocabulary learning linguists cannot limit the investigation of the process of vocabulary learning to word meaning (Gass, 1999). Since many questions remain unsettled in this domain, this study was conducted in the context of TEFL to investigate the effect of teaching vocabulary through its use in contexts in which learners have an interest versus contexts in which they are not that much interested. It, therefore, examines the impact(s) of contextual vocabulary learning and attempts to have a comparison of the effect(s) of the role of favored contexts as opposed to disfavored contexts. The experiment involved two groups of twenty-five male Iranian participants aged from 15 to 25 at the intermediate level in an Iranian English language institute. All things considered, a pretest-posttest control group design was determined to check the accuracy of the researchers' hypothesis in a short-term treatment through the application of reading comprehension tests (RCT). As a result, the overall findings support the initial idea that second language vocabulary acquisition (SLVA) is better achieved through the use of favored-contexts.
\end{abstract}

Keywords: Second language, Vocabulary learning, Favored-contexts

\section{Introduction}

It seems almost impossible to overstate the power of words; they literally have changed and will continue to change the course of world history. Perhaps the greatest tools we can give students for succeeding, not only in their education but more generally in life, is a large, rich vocabulary and the skills for using those words. Our ability to function in today's complex social and economic world is mightily affected by our language skills and word knowledge. It has been estimated that some 60 percent of today's world population is multilingual. From both a contemporary and historical perspective, bilingualism or multilingualism is the norm rather than the exception. It is fair, then to say that throughout history foreign language learning has always been an important practical concern. (Richards, 2001, p. 3)

In addition to the vital importance of vocabulary for success in life, a large vocabulary is more specifically predictive and reflective of high levels of reading achievement. The Report of the National Reading Panel (2000), for example, concluded, "The importance of vocabulary knowledge has long been recognized in the development of reading skills. As early as 1924, researchers noted that growth in reading power relies on continuous growth in word knowledge" (The Report of the National Reading Panel, 2000, p. 4-15). In his article published in 1997, Zimmerman makes a reference to the central role of vocabulary and states: "Vocabulary is central to language and of critical importance to the typical language learner" (Zimmerman, 1997, p. 121-140). The prominent role of vocabulary knowledge in foreign language learning has been increasingly recognized (Rodriguez \& Sadoski, 2000, p. 385-412).

From decades ago many teaching methods have emerged, and all of them, in one way or another have considered the teaching of vocabulary. For instance, Grammar-Translation method has been used by language teachers for many years. Diane Larsen-Freeman in her book titled "Techniques and Principles in Language Teaching", in the 
definition of Grammar-Translation Method says: "At one time it was called the Classical Method since it was first used in the teaching of the classical languages, Latin and Greek" (Larsen-Freeman, 2000, p.11). From another perspective, Jack C. Richards attracts our attention to another characteristic of Grammar-Translation Method:
"In GTM vocabulary selection is based solely on the reading text used, and words are taught through bilingual word lists, dictionary study, and memorization. In a typical Grammar-Translation text a list of vocabulary items is presented with their translation equivalent, and translation exercises are prescribed" (Richards, 2001, p. 6).

In 1900, the Direct Method, sometimes called Natural Method, came into the scene of foreign language teaching. Based on its features, only EVERYDAY vocabulary and sentences are taught (The language is made real).Larsen-Freeman, defining the characteristics of the Direct Method, states: "Vocabulary is acquired more naturally if students use it in full sentences, rather than memorizing word lists. Vocabulary is emphasized over grammar" (Larsen-Freeman, 2000, p. 27-29).

Jack c. Richards, while preparing a background on the Oral Approach and Situational Language Teaching, on the section of vocabulary control, argues that:
"In 1920s and 1930s, several large-scale investigations of foreign language vocabulary were undertaken, the impetus of which came from two quarters. First there was a general consensus among language teaching specialists, such as Palmer, that vocabulary was one of the most important aspects of foreign language learning. A second influence was the increased emphasis on reading skills as the goal of foreign language studies in some countries. This led to the development of principle of vocabulary control, which was to have a major practical impact on the teaching of English in subsequent decades" (Richards, 2001, p.37).

Another prominent teaching method which deserves mentioning is Content-Based approach. Content-Based instruction (CBI) refers to the teaching of content or information in the language being learned with little or no direct or explicit effort to teach the language itself separately from the content being taught. (Krahnke, 1987). Larsen-Freeman, on the role of Content-Based approach in vocabulary teaching argues that: "Vocabulary is easier to acquire when there are contextual clues to help convey the meaning" (Larson-Freeman, 2000, p. 140).

Having mentioned the importance of vocabulary teaching in the framework of some major teaching methods and its contribution to the lives of second language learners, this study aims at pinpointing the salient role of vocabulary and the way of boosting its role via learning words in context, and is trying to explore the influence of teaching vocabulary in favored-contexts.

\section{Statement of the Problem}

In the recent past, a lot has been done on second language vocabulary acquisition (SLAVA). The last twenty-five years has been seen as an explosion of experimental research in such a field (Nielson, 2001). More specifically, seeing vocabulary in rich contexts provided by authentic texts rather than in isolated vocabulary drills produces robust vocabulary learning (National Reading Panel, 2000). Interestingly, most of the new words that students learn are actually learned in context; relatively few are learned through direct instruction (Beck \& McKeown, 1991, p. 3-23; Nagy \& Herman, 1987, p. 237-270). Mostly, contextualized vocabulary learning, as opposed to de-contextualized vocabulary learning, has been agreed upon as an effective vocabulary learning strategy. Peter Ynagki $\mathrm{Gu}$, in his study published in the year 2003 on the role of vocabulary learning in second language makes a reference to the work of McCarthy (1990) in which he states that: "a word learned in a meaningful context is best assimilated and remembered". In fact, learning new words from context might well be only the first step learners employ (Ynagki, 2003). Above all, very few studies have been previously done on the significant role favored-contexts may play on vocabulary learning. This being so, the researcher has been inspired to conduct an introductory research on the possible effects of favored-contexts on second language vocabulary acquisition (SLVA). In fact, this study is conducted to indicate the possible effects of teaching vocabulary through contexts in which learners have no interest and to have a comparison with the possible effects of teaching vocabulary through contexts in which learners are strongly interested. This being so, three hypotheses can be generated at the outset of this study:

Null Hypothesis: there is no relationship between teaching vocabularies through favoredcontexts and better retention of vocabulary by learners.

Hypothesis 1: there is a positive relationship between teaching vocabularies through

Favored-contexts and better retention of vocabulary by learners. 
Hypothesis 2: there is a negative relationship between teaching vocabularies through

Favored-contexts and better retention of these vocabularies by learners.

\section{Review of Literature}

Recently, there has been an increased awareness of the role of vocabulary acquisition with regard to the foreign learner (Zimmerman, 1997, p. 121-140). Contemporary studies in reading and L2 vocabulary acquisition often cite the work of Michael West (1953). His work is highly relevant to reading and second language acquisition.

Jack C. Richards mentions the work of Michael West on frequency-based analyses of vocabulary in 1953: "Michael West in his work states that: 'It is agreed that in order to expedite English language acquisition, the foreign student would benefit most by becoming familiar with those words most commonly encountered in text'." (Richards, 2001, p. 135). By 1953, Michael West assembled "A General Service List of English Words", comprising the 2,000 most frequently used words found in English text. This task was accomplished by compiling a running text of five million words taken from a broad selection of reading material; words were then tabulated on the basis of frequency.

Peter Ynagki Gu, in his study published in the year 2003 on the role of vocabulary learning in second language, made a reference to the work of Nation and Newton (1997) in which they concluded that: "Focusing learners' attention on the high-frequency words of the language gives a very good return for the learning effort" (Nation and Newton, 1997, p. 238-254). He also mentions Coady's idea of learning high-frequency words: "These words should be learned to the point of automaticity" (Coady, 1993, p .3-23).

Peter Ynagki Gu in his article "Vocabulary Learning in Second Language" draws on the study done by McCarthy, in 1984, in which he mentions:

"One way to see the overall task of vocabulary learning is through the distinction between knowing a word and using a word. In other words, the purpose of vocabulary learning should include both remembering words and the ability to use them automatically in a wide range of language contexts when the need arises" (McCarthy, 1984, p. 12-22).

By referring to work of Ellis we can conclude that: the knowledge aspect (both breadth and depth) requires more conscious and explicit learning mechanisms whereas the skill aspect involves mostly implicit learning and memory (Ellis, 1994, p. 37-56). Vocabulary learning strategies, therefore, should include strategies for "using" as well as "knowing" a word.

Guessing and Vocabulary Learning:

In his article "Research on ESL/EFL vocabulary acquisition", Coady states that: "the vast majority of words in L1 come from extensive and multiple exposures through use rather than direct instruction, and therefore, vocabulary learning in a second language should follow the same route" (Coady, 1993, p. 3). An important question then to ask is: Does guessing lead to incidental vocabulary learning in a second language?

Malatesha Joshi, in his article published in 2005, mentions the work of Nagy, Anderson and Herman saying that: "Ample evidence suggests that children learn a large proportion of their L1 vocabulary incidentally from reading and listening (Nagy, Anderson, \& Herman, 1987, p. 237-270). Joshi states that: "Nagy, Anderson, and Herman estimated an average vocabulary growth of 1,000 words a year for the children in their study. Fewer studies have been carried out in second or foreign language contexts. What we have, does suggest a similar pattern" (Joshi, 2005, p. 209-219). Ynagki in his article published in 2003 says:

"In a study done by Ferris (1988), 30 adult ESL students read George Orwell's novel Animal Farm. A multiple-choice test of 75 words was given to these subjects before and after they read the novel and to a control group of 21 international students who did not read the novel. The experimental group who read the novel made significantly better gains than the control group.

The intentional and direct learning of vocabulary does not, and should not, rule out contextual learning. In fact, learning new words from context might well be only the first step learners employ, and they should carry on, with metacognitive choice of words and treatment, to encode the new word together with the context where it appears (e.g., remembering the word together with the surrounding sentence). Regarding the use of context on the part of the learners, Ynagki, in his study, refers to Sanaoui who believes that: "Some may even try to create a sentence using the new word and thus put it back into context (Sanaoui, 1995, p. 15-28). Most empirical studies on contextual learning have compared incidental vocabulary learning from context with other forms of vocabulary presentation.

By considering tones of studies in the field of vocabulary learning and teaching, one can say, without a doubt, that vocabulary is one of the strongest building blocks in the task of second language learning. Learners choose multiple strategies in order to be able to remember and use vocabularies in communication. Many methods of English 
teaching as a foreign/second language also emphasize teaching of vocabulary in a way that yields the most efficient and the best retention time. Many have mentioned and discussed vocabulary teaching via relevant contexts. This study is conducted to see the difference between the influence of teaching vocabulary in normal contexts and in favored-contexts (those in which learners are strongly interested).

\section{Methodology}

\subsection{Participants}

All in all, fifty-two Iranian subjects participated in this study. All of them were studying English in one of the institutes in Isfahan (Iran); and were in various age groups ranging from fifteen to twenty-five. Due to the limitations of the researcher, two intact classes were chosen for such a research. It is surely necessary to point out that two participants were eliminated at last because they were absent for almost half of the treatment sessions. Bearing in mind that the possibility of any impact of favored passages on SLVA was the main purpose of the current study, a control group was fixed on. It also would be worth noting that, from the outset of the study, forty-one students of the same institute were given a questionnaire to choose their most favorite subject of study as well as the one they would rather avoid reading about, the result of which is shown below (cf. Appendix 1). These students were randomly chosen from five different classes. (insert Table 1 here)

\subsection{Design}

Such study was designed in a pre-test post-test control group manner which is classified as one of the sub-categories of pre-experimental designs. Two intact groups were chosen (there was no randomization of participants due to the limitations of the study). To allocate the control or experimental group to each of the classes available, the researchers for the goal of being as unbiased as possible, employed a randomization strategy so that class A was labeled the experimental group and class B the control group.

\subsection{Material}

All of the materials of the current study were prepared by the researcher. The pre-test and post-test were each composed of a sport passage and a geography passage followed by ten multiple-choice questions for each topic. Too, eight treatment passages (four about sport and four about geography) were designed to be taught in four consecutive sessions which were held every other day. There was no priority for the passages taught in the class and the students were free to choose which passage they want to read first. Each passage in this study was written in two or three paragraphs in which ten new words to be taught-almost those which were not in the syllabus of the books taught in the institute-were underlined to attract the attention of the students.

\subsection{Procedure}

First of all, two approximately homogeneous classes were chosen by the researcher and a couple of weeks were given them to adjust themselves with the class. Then the pre-test was administered in order to draw out the primary behavior of the participants in groups A and B. After almost a week, the participants in group A were taught eight passages in four sessions as the treatment. In each session the students were asked to read the first passage silently for four or five minutes, elaborate on it with some questions, and also give a very concise summary of it. Up to this point, no vocabulary was explicitly taught. The teacher might, one way or another, help them understand the meaning of the sentences, though. After the summary some words, asked by the students, were taught explicitly and others were left untouched. The next ten minutes was allocated to the second passage. It should be well noted that no treatment was set in group B. Two weeks after the last session of the treatment, the post-test was administered without a notice in order to check the real effect of such treatment. It is important to mention that students were not aware of the underlying purpose of such work. In view of that, a questionnaire including a two-choice question was administered at the end of the posttest to make sure that the participants of the study were all interested in "sport". (cf. Appendix.2).

\subsection{Results}

Table 2 is presented to show the scores of our twenty-five subjects in the experimental group from pretest (Sport \& Geography). Every subject has been given a nominal code from one to twenty-five. It is noteworthy that these numbers do not indicate any rank or order among the participants (they lack any mathematical value). (insert Table 2 here)

Table 3 is presented to show a simplified presentation of scores obtained from the sport pretest in experimental group.

Figure 2 is presented to show a simplified presentation of scores obtained from the geography pretest in experimental group. (insert Figure 2 here) 
To be able to have an exhaustive comprehension of how each participant did on the geography pretest, and to be able to have a comparison with its posttest counterpart. (insert Figure 3 here)

Table 4 shows the frequency of the scores in sport and geography pretests in experimental group according to which we conclude that scores are normally distributed. (insert Table 4 here)

Table 5 is presented to show the scores of our twenty-five subjects in experimental group from posttest (Sport \& Geography). Every subject has been given a nominal code from one to ten. It is noteworthy that these numbers do not indicate any rank or order among the participants (they lack any mathematical value). (insert Table. 5 here)

The mean $(\bar{x})$ and the standard deviation (SD) of the scores obtained are shown in Table 6. Table 6, simplified presentation of scores obtained from the sport posttest in experimental group.

To see a simplified presentation of scores obtained from the geography posttest in experimental group. (insert figure 6 here)

To be able to have an exhaustive comprehension of how each participant did on the sport posttest, and to be able to have a comparison with its pretest counterpart. (insert Figure 7 here)

To be able to have an exhaustive comprehension of how each participant did on the geography posttest, and to be able to have a comparison with its pretest counterpart. (insert Figure 8 here)

In order to be able to compare the results of the sport passages (pretest $\&$ posttest) and to be able to observe the possible effects of our treatment. (insert Figure 9 here)

In order to be able to compare the results of the geography passages (pretest $\&$ posttest) and to be able to observe the possible effect of our treatment. (insert Figure 10 here)

The above demonstrations were a comprehensive analysis of the data regarding the scores obtained from pretest and posttest in the experimental group. Due to the insignificance of the data obtained from the control group, the following figures and tables are presented in a concise manner.

Insert Table 8 here to observe the scores obtained from pretest sport and geography in control group.

Table 9 shows the mean $(\bar{x})$ and the standard deviation (SD) of the scores obtained.

Insert Table.10 here to observe the scores obtained from posttest sport and geography in control group.

Table 11 shows the mean $(\bar{x})$ and the standard deviation (SD) of the scores obtained.

Insert Table. 12 to observe the frequency of the scores in sport and geography pretests in control group.

Insert Table.13 here to observe the frequency of the scores in sport and geography posttests in control group.

Based on the data obtained, a t-value of -24.3 with 48 d.f. (degree of freedom) is significant at the 0.05 level. A value of 0.05 indicates that there is only a $5 \%$ probability that the research findings are due to chance rather than to an actual relationship between or among variables (Mackey \& Gass, 2005, p.265). Therefore we have evidence to support the claim that the strategies employed by the teacher to teach vocabularies through contexts (treatment) have been verified to be viable both in sport and geography texts. (Table 14)

However, in order to verify the main hypothesis of this study (hypothesis 1), two paired t-tests (one for scores obtained from sport pretest and posttest; one for scores obtained from geography pretest and posttest) were calculated.

Sport pre-test post-test t-test (Table 15)

Based on the values obtained, $t$-values with 24 d.f. are significant enough at the level of 0.05 to support the effectiveness of the treatment in both subjects of study.

As it can be inferred from the difference between the t-value obtained from scores of sport pretest and posttest (-16) and t-value obtained from scores of geography pretest and posttest (-18.3), it could be concluded that the participants have not performed better in sport passages than geography ones. So, hypothesis. 1 mentioned at the beginning of the study is rejected. Hypothesis 2 is confirmed.

\section{Discussion}

After all these, a logical question may arise that why the researchers have chosen to incorporate the explicit approach in the instruction of vocabulary in their experiment. A sound answer may well be found in related literature on vocabulary acquisition. For instance, Paribakht and Wesche (1997) conducting an empirical study found out that instruction plays a crucial role in gaining more vocabularies both quantitatively and qualitatively. For this and other well justified reasons all the vocabularies taught in this study were taught explicitly. 
The results obtained from this research stress the role of interest and the motivation caused by it in learners' language vocabulary acquisition. In this light, material designers should heed more attention accordingly while designing books for language learners. It is suggested that students' needs, preferences and interest areas be identified prior to designing the intended material, specially reading passages and activities.

These all mentioned, language learners should also be aware of the significant impact of interest as an affective factor in vocabulary acquisition through reading activities and can act based on the findings of this research especially in their self-studies.

\section{Further Research}

As far as it is related to the interest of the learners in reading tasks, the Iranian context yielded results different from those of other researches done in different contexts and with different participants. Hence further studies of this kind are suggested to be done in contexts in which the material designers and or instructors are not aware of the interest areas of their language learners since not a universal prescription can be provided for all contexts and teaching and learning situations, reading tasks and vocabulary acquisition.

\section{References}

Beck, I. L., \& McKeown, M. G. (1991). Conditions of vocabulary acquisition. Handbook of reading research, Vol. 2. Beck, Isabel; McKeown, Margaret Barr, Rebecca (Ed); Kamil, Michael L. (Ed); Mosenthal, Peter B. (Ed); Pearson, P. David. (Ed), Handbook of reading research, Vol. 2, 789-814. Hillsdale, NJ, England: Lawrence Erlbaum Associates, Inc.

Coady, J. (1993). Research on ESL/EFL vocabulary acquisition: Putting it in context. Norwood, N.J: Ablex.

Ellis, N. (1994). Consciousness in second language learning: Psychological perspectives on the role of conscious processes in vocabulary acquisition. University College of North Wales.

Ferris, D. (1988). Reading and second language vocabulary acquisition. Unpublished manuscript. Department of Linguistics, University of Southern California.

Gass, S. (1999). Incidental vocabulary learning. SSLA, 21, 319. United States of America: Cambridge University Press.

Joshi, M. (2005). Vocabulary: a critical component of comprehension. Reading and writing quarterly, 21, 209-219. http://dx.doi.org/10.1080/10573560590949278

Krahnke, K. (1987). Approaches to syllabus design for foreign Language teaching. New York: Prentice Hall.

Larson Freeman, D. (2000). Techniques and principles in language teaching. (2nd ed). Oxford: Oxford University Press.

Mackey, A., \& Gass, S. M. (2005). Second language research, methodology and design. New Jersey: Lawrence Erlbaum Associates, Inc., Publishers.

McCarthy, M. J. (1984). A new look at vocabulary in EFL. Applied Linguistics, 5, 12-22. http://dx.doi.org/10.1093/applin/5.1.12

McCarthy, M. J. (1990). Vocabulary. Oxford: Oxford University Press.

Nagy, W., Anderson, R., \& Herman, P. (1987). Learning word meanings from context during normal reading. American Educational Research Journal, 24, 237-270

National reading panel. (2000). Report of the national reading panel: Teaching children to read, 4-15. Washington. D. C.: National Institute of Child Health and Human Development.

Nation, P., Newton, J. (1997). Teaching vocabulary. The Cambridge applied linguistics series. New York: Cambridge University Press.

Nielson, B. M. (2001). The Effectiveness of sentence generation on the acquisition of receptive and productive knowledge of explicitly presented lexical Items. University of Wollongog, New Australia.

Paribakht, T. S., \& Wesche, M. (1997). Vocabulary enhancement activities and reading for meaning in second language vocabulary acquisition. In J, Coady, \& T, Huckin (Eds.), second language vocabulary acquisition: a rationale for pedagogy. New York: Cambridge University Press.

Richard, C. Jack. (2001). Approaches and methods in language teaching. (2nd ed). Cambridge: The Press Syndicate of the University of Cambridge.

Rodriguez, M., \& Sadoski, M. (2000). Effects of rote, context, keyword, and context/ keyword methods on retention 
of vocabulary in EFL classrooms. Language Learning, 50, 2, 385- 412

Sanaoui, R. (1995). Adult learners' approaches to learning vocabulary in second languages. The Modern Language Journal, 79, 15-28

West, M. (1953). A general service list of English words. London: Longman Group.

Ynagki, G. P (2003). Vocabulary learning in a second language, person, task, context and strategies. TESL-EJ, 7, 2

Zimmerman, C. (1997). Do reading and interactive vocabulary Instruction make a difference? an empirical Study.

TESOL Quarterly, 31, 121- 140. http://dx.doi.org/10.2307/3587978

Table 1. Sampling of students based on their favorite context

\begin{tabular}{|l|l|l|}
\hline & Like & Dislike \\
\hline Sport & 14 & 1 \\
\hline Animal & 4 & 3 \\
\hline Geography & 4 & 7 \\
\hline History & 2 & 6 \\
\hline
\end{tabular}

Table 2. Scores obtained from pretest Geography and Sport in experimental group

\begin{tabular}{|ll|l|l|l|l|l|l|l|l|l|l|}
\hline & & $\mathbf{1}$ & $\mathbf{2}$ & $\mathbf{3}$ & $\mathbf{4}$ & $\mathbf{5}$ & $\mathbf{6}$ & $\mathbf{7}$ & $\mathbf{8}$ & $\mathbf{9}$ & $\mathbf{1 0}$ \\
\hline Pretest & $\mathbf{( S )}$ & 4 & 3 & 4 & 2 & 2 & 4 & 3 & 3 & 3 & 5 \\
\hline $\begin{array}{l}\text { Pretest } \\
(\mathbf{G})\end{array}$ & 5 & 5 & 5 & 3 & 5 & 2 & 3 & 3 & 8 & 5 \\
\hline
\end{tabular}

\begin{tabular}{|l|l|l|l|l|l|l|l|l|l|l|l|l|l|l|}
\hline $\mathbf{1 1}$ & $\mathbf{1 2}$ & $\mathbf{1 3}$ & $\mathbf{1 4}$ & $\mathbf{1 5}$ & $\mathbf{1 6}$ & $\mathbf{1 7}$ & $\mathbf{1 8}$ & $\mathbf{1 9}$ & $\mathbf{2 0}$ & $\mathbf{2 1}$ & $\mathbf{2 2}$ & $\mathbf{2 3}$ & $\mathbf{2 4}$ & $\mathbf{2 5}$ \\
\hline 2 & 5 & 4 & 3 & 6 & 4 & 1 & 2 & 5 & 3 & 5 & 6 & 3 & 7 & 4 \\
\hline 4 & 4 & 3 & 3 & 4 & 2 & 7 & 4 & 6 & 2 & 6 & 4 & 2 & 3 & 3 \\
\hline
\end{tabular}

Table 3. To show a simplified presentation of scores obtained from the sport pretest in experimental group.

\begin{tabular}{|l|l|l|}
\hline & $\bar{x}$ & SD \\
\hline Pretest (s) & 3.72 & 1.34 \\
\hline Pretest (G) & 4.16 & 159 \\
\hline & & \\
\hline
\end{tabular}

Table 4. Table of frequency (sport and geography pretest scores)

\begin{tabular}{|l|l|l|l|l|l|l|l|l|}
\hline Scores & $\mathbf{1}$ & $\mathbf{2}$ & $\mathbf{3}$ & $\mathbf{4}$ & $\mathbf{5}$ & $\mathbf{6}$ & $\mathbf{7}$ & $\mathbf{8}$ \\
\hline Frequency (sport pretest) & 1 & 4 & 7 & 6 & 4 & 2 & 1 & 0 \\
\hline Frequency (geography pretest) & 0 & 4 & 7 & 5 & 5 & 2 & 1 & 1 \\
\hline
\end{tabular}


Table 5. Scores obtained from posttest, Geography (G) and Sport (S) in experimental group

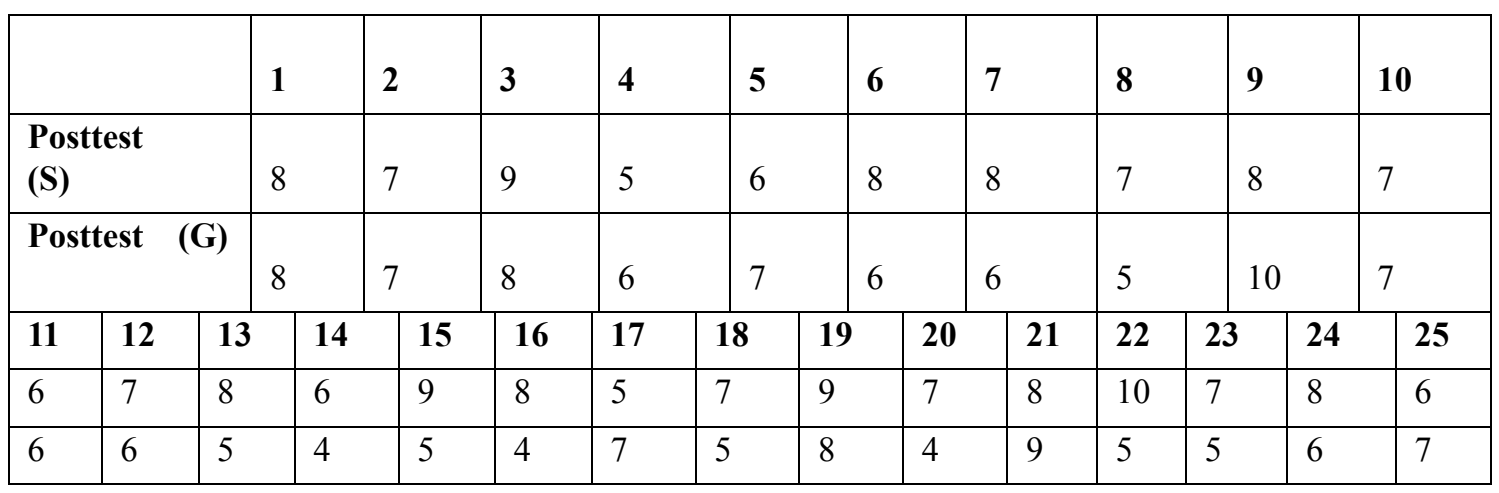

Table 6. To show a simplified presentation of scores obtained from the sport posttest in experimental group.

\begin{tabular}{|l|l|l|}
\hline & $\bar{x}$ & SD \\
\hline Posttest (s) & 7.36 & 1.24 \\
\hline Posttest (G) & 6.24 & 1.55 \\
\hline
\end{tabular}

Table 7. Table of frequency (sport posttest scores)

\begin{tabular}{|l|l|l|l|l|l|l|l|}
\hline Scores & $\mathbf{4}$ & $\mathbf{5}$ & $\mathbf{6}$ & $\mathbf{7}$ & $\mathbf{8}$ & $\mathbf{9}$ & $\mathbf{1 0}$ \\
\hline Frequency (sport posttest) & 0 & 2 & 4 & 7 & 8 & 3 & 1 \\
\hline Frequency (geography posttest) & 3 & 6 & 6 & 5 & 3 & 1 & 1 \\
\hline
\end{tabular}

Table 8. Scores obtained from pretest sport and geography in control group

\begin{tabular}{|l|l|l|l|l|l|l|l|l|l|l|}
\hline & $\mathbf{1}$ & $\mathbf{2}$ & $\mathbf{3}$ & $\mathbf{4}$ & $\mathbf{5}$ & $\mathbf{6}$ & $\mathbf{7}$ & $\mathbf{8}$ & $\mathbf{9}$ & $\mathbf{1 0}$ \\
\hline $\begin{array}{l}\text { Pretest } \\
\text { (S) }\end{array}$ & 5 & 2 & 3 & 3 & 3 & 4 & 3 & 2 & 5 & 2 \\
\hline $\begin{array}{l}\text { Pretest } \\
\text { (G) }\end{array}$ & 4 & 3 & 3 & 6 & 2 & 1 & 2 & 2 & 5 & 3 \\
\hline
\end{tabular}

\begin{tabular}{|l|l|l|l|l|l|l|l|l|l|l|l|l|l|l|}
\hline $\mathbf{1 1}$ & $\mathbf{1 2}$ & $\mathbf{1 3}$ & $\mathbf{1 4}$ & $\mathbf{1 5}$ & $\mathbf{1 6}$ & $\mathbf{1 7}$ & $\mathbf{1 8}$ & $\mathbf{1 9}$ & $\mathbf{2 0}$ & $\mathbf{2 1}$ & $\mathbf{2 2}$ & $\mathbf{2 3}$ & $\mathbf{2 4}$ & $\mathbf{2 5}$ \\
\hline 3 & 4 & 4 & 3 & 1 & 4 & 6 & 5 & 4 & 5 & 3 & 4 & 4 & 3 & 2 \\
\hline 3 & 4 & 1 & 3 & 1 & 4 & 5 & 4 & 3 & 4 & 2 & 3 & 2 & 3 & 4 \\
\hline
\end{tabular}

Table 9. The mean $(\bar{x})$ and the standard deviation (SD) of the scores obtained.

\begin{tabular}{|l|l|l|}
\hline & $\bar{x}$ & SD \\
\hline Posttest (s) & 3.48 & 1.19 \\
\hline Posttest (G) & 3.08 & 1.19 \\
\hline & & \\
\hline
\end{tabular}


Table 10. Scores obtained from posttest sport and geography in control group

\begin{tabular}{|l|l|l|l|l|l|l|l|l|l|l|}
\hline & $\mathbf{1}$ & $\mathbf{2}$ & $\mathbf{3}$ & $\mathbf{4}$ & $\mathbf{5}$ & $\mathbf{6}$ & $\mathbf{7}$ & $\mathbf{8}$ & $\mathbf{9}$ & $\mathbf{1 0}$ \\
\hline $\begin{array}{l}\text { Posttest } \\
\text { (S) }\end{array}$ & 4 & 6 & 2 & 3 & 4 & 3 & 3 & 3 & 2 & 1 \\
\hline $\begin{array}{l}\text { Posttest } \\
\text { (G) }\end{array}$ & 4 & 4 & 3 & 4 & 3 & 5 & 2 & 4 & 3 & 1 \\
\hline
\end{tabular}

\begin{tabular}{|l|l|l|l|l|l|l|l|l|l|l|l|l|l|l|}
\hline $\mathbf{1 1}$ & $\mathbf{1 2}$ & $\mathbf{1 3}$ & $\mathbf{1 4}$ & $\mathbf{1 5}$ & $\mathbf{1 6}$ & $\mathbf{1 7}$ & $\mathbf{1 8}$ & $\mathbf{1 9}$ & $\mathbf{2 0}$ & $\mathbf{2 1}$ & $\mathbf{2 2}$ & $\mathbf{2 3}$ & $\mathbf{2 4}$ & $\mathbf{2 5}$ \\
\hline 3 & 3 & 4 & 2 & 1 & 5 & 4 & 1 & 2 & 6 & 5 & 2 & 3 & 4 & 3 \\
\hline 1 & 5 & 2 & 4 & 2 & 1 & 3 & 6 & 4 & 3 & 3 & 2 & 4 & 5 & 3 \\
\hline
\end{tabular}

Table 11. The mean $(\bar{x})$ and the standard deviation (SD) of the scores obtained.

\begin{tabular}{|l|l|l|}
\hline & $\bar{x}$ & SD \\
\hline Posttest (s) & 3.16 & 1.58 \\
\hline Posttest (G) & 3.24 & 1.34 \\
\hline & & \\
\hline
\end{tabular}

Table 12. Shows the frequency of the scores in sport and geography pretests in control group

\begin{tabular}{|l|l|l|l|l|l|l|}
\hline Scores & $\mathbf{1}$ & $\mathbf{2}$ & $\mathbf{3}$ & $\mathbf{4}$ & $\mathbf{5}$ & $\mathbf{6}$ \\
\hline Frequency (sport pretest) & 1 & 4 & 8 & 7 & 4 & 1 \\
\hline Frequency (geography pretest) & 3 & 5 & 8 & 6 & 2 & 1 \\
\hline
\end{tabular}

Table 13. Shows the frequency of the scores in sport and geography posttests in control group

\begin{tabular}{|l|l|l|l|l|l|l|}
\hline Scores & $\mathbf{1}$ & $\mathbf{2}$ & $\mathbf{3}$ & $\mathbf{4}$ & $\mathbf{5}$ & $\mathbf{6}$ \\
\hline Frequency (sport pretest) & 3 & 5 & 8 & 5 & 2 & 2 \\
\hline Frequency (geography pretest) & 3 & 4 & 7 & 7 & 3 & 1 \\
\hline
\end{tabular}

Table 14. The strategies employed by the teacher to teach vocabularies through contexts (treatment) have been verified to be viable both in sport and geography texts

\begin{tabular}{|l|l|l|l|}
\hline $\begin{array}{l}\sum \mathrm{x}=194 \\
\sum \mathrm{y}=340\end{array}$ & $\sum \mathrm{D}=148$ & $\mathrm{SD}=0.92$ & $\mathrm{t}=-24.3$ \\
\hline $\bar{x} \mathbf{1}=3.88$ & & & \\
$\bar{x} \mathbf{2}=3.88$ & $\sum \mathrm{D} 2=480$ & $\mathrm{SD}$ bar $=0.12$ & \\
\hline
\end{tabular}


Table 15. Sport pre-test post-test t-test

\begin{tabular}{|l|l|l|l|}
\hline$\sum \mathrm{X}=144$ & $\sum \mathrm{Y}=184$ & $\sum \mathrm{D}=91$ & $\mathrm{t}=-16$ \\
\hline $\bar{x} 1=5.7$ & $\bar{x} 2=7.3$ & $\sum \mathrm{D}^{2}=128$ & \\
\hline
\end{tabular}

\begin{tabular}{|l|l|l|l|}
\hline$\sum \mathrm{X}=101$ & $\sum \mathrm{Y}=156$ & $\sum \mathrm{D}=55$ & \\
\hline $\bar{x} 1=4.4$ & $\bar{x} 2=7.0$ & $\sum \mathrm{D}^{2}=131$ & \\
\hline
\end{tabular}

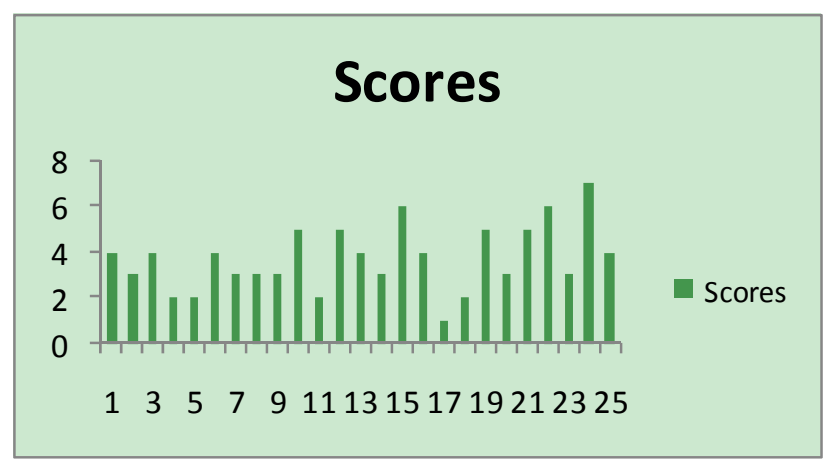

Figure 1. Scores obtained from pretest Sport in experimental group

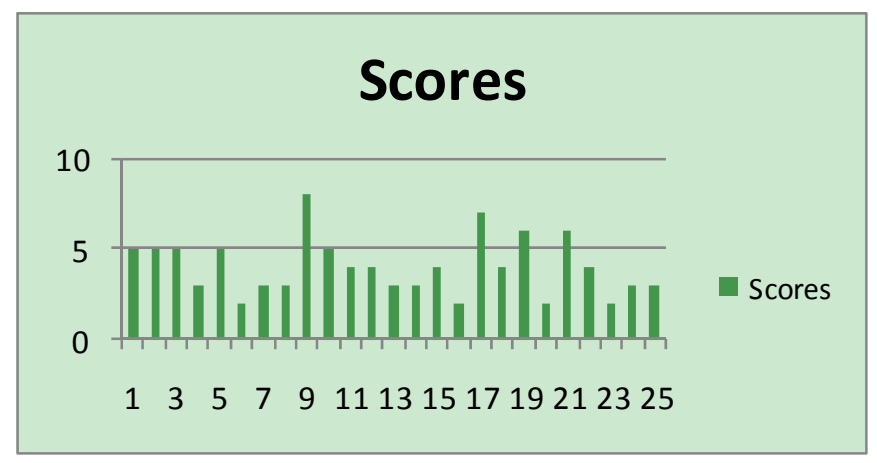

Figure 2. Scores obtained from pretest Geography in experimental group

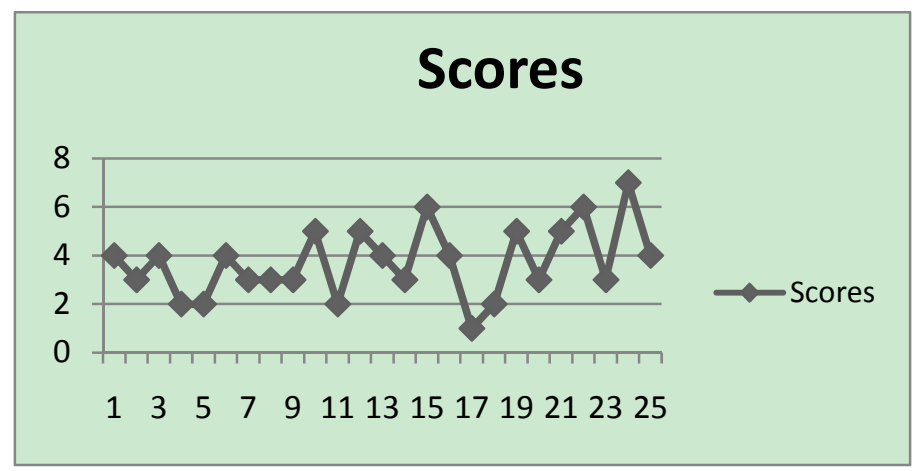

Figure 3. Polygon showing the scores of sport pretest (experimental group) 


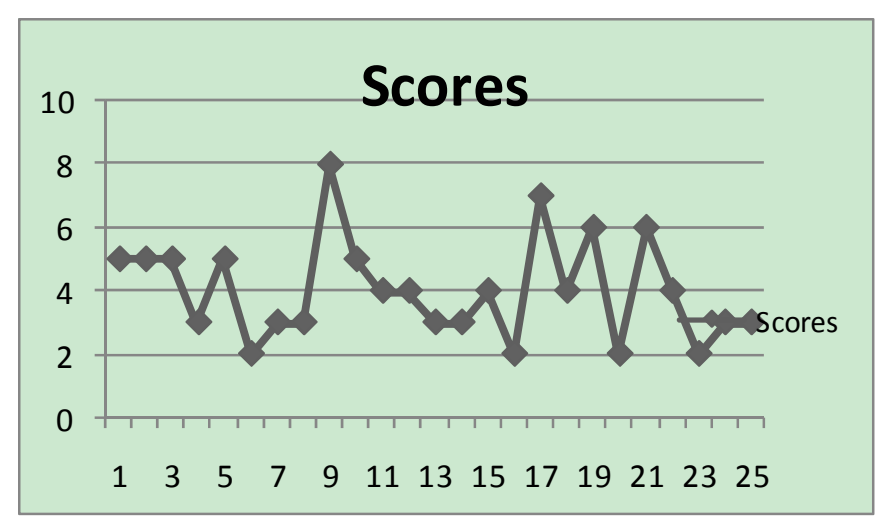

Figure 4. Polygon showing the scores of geography pretest (experimental group)

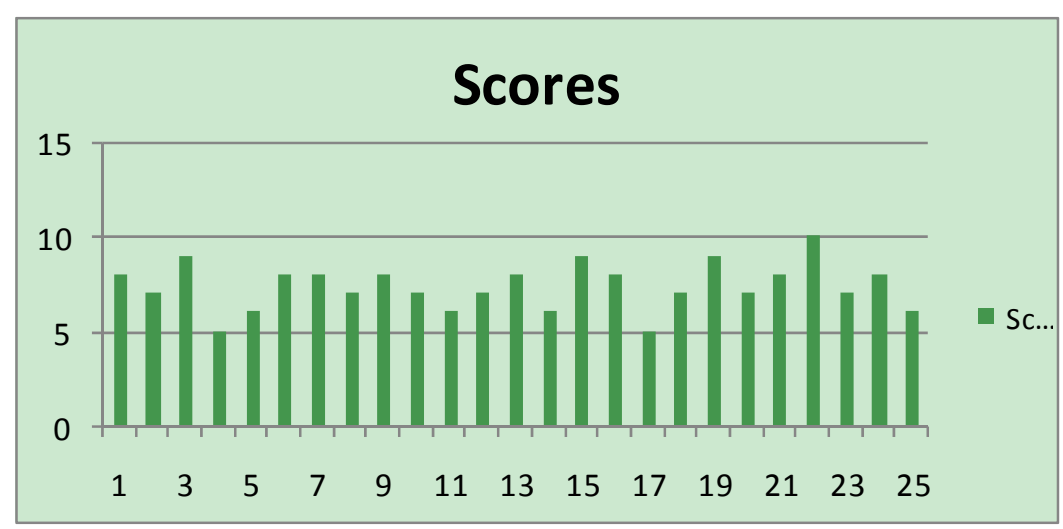

Figure 5. Scores obtained from posttest Sport in experimental group

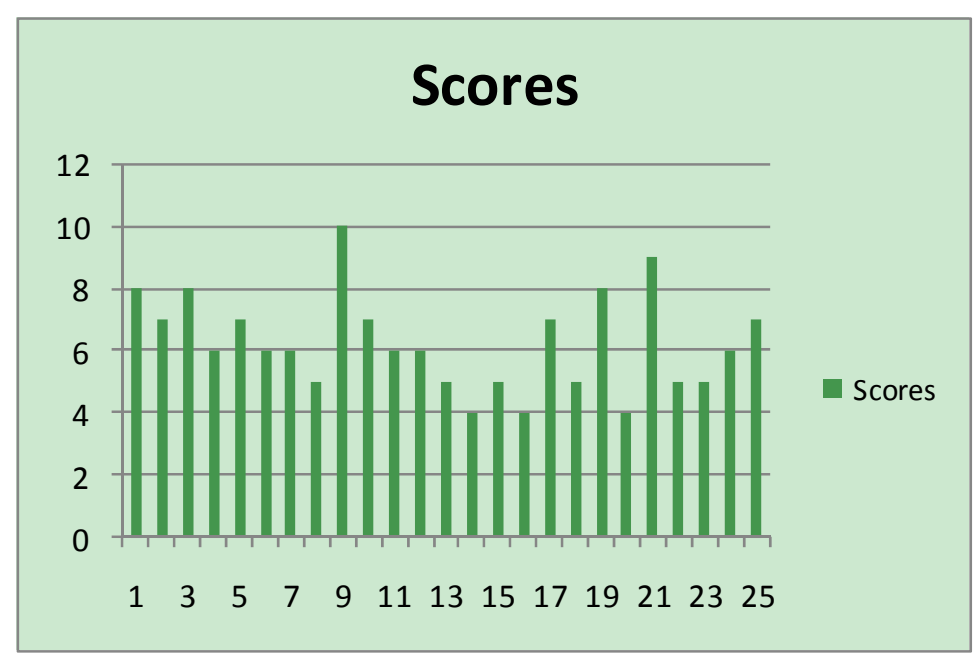

Figure 6. Scores obtained from posttest Geography in experimental group 


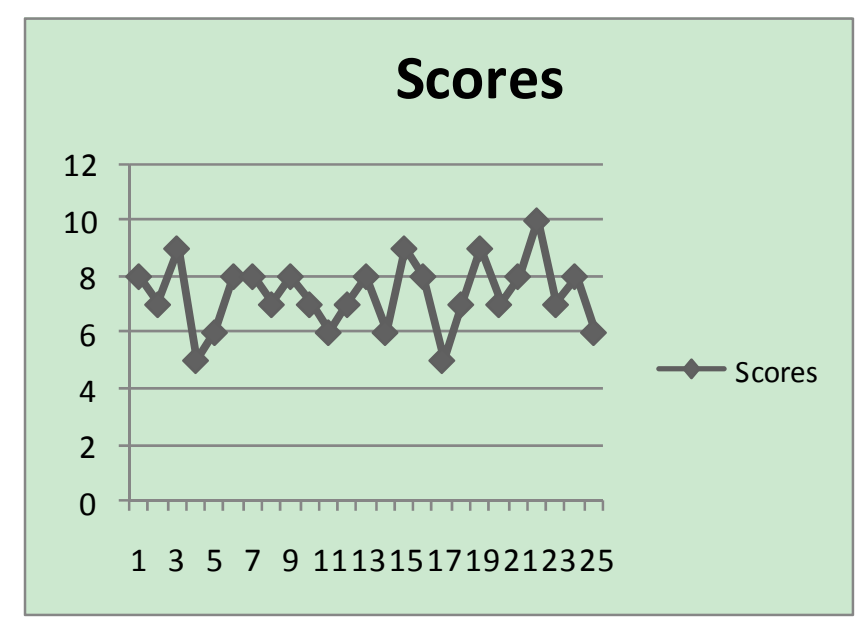

Figure 7. Polygon showing the scores of sport posttest (experimental group)

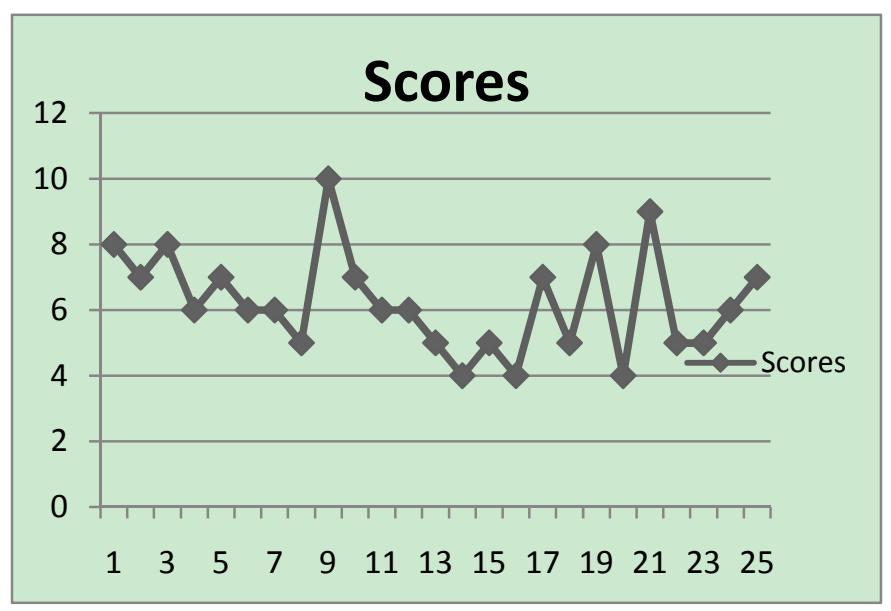

Figure 8. Polygon showing the scores of geography posttest (experimental group)

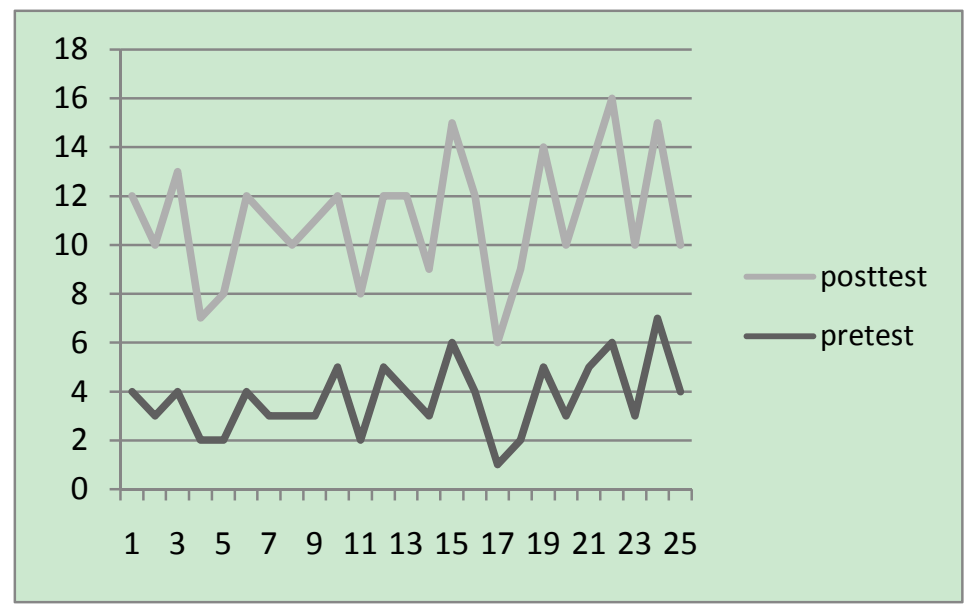

Figure 9. Comparison of sport scores in pretest and posttest (experimental group) 


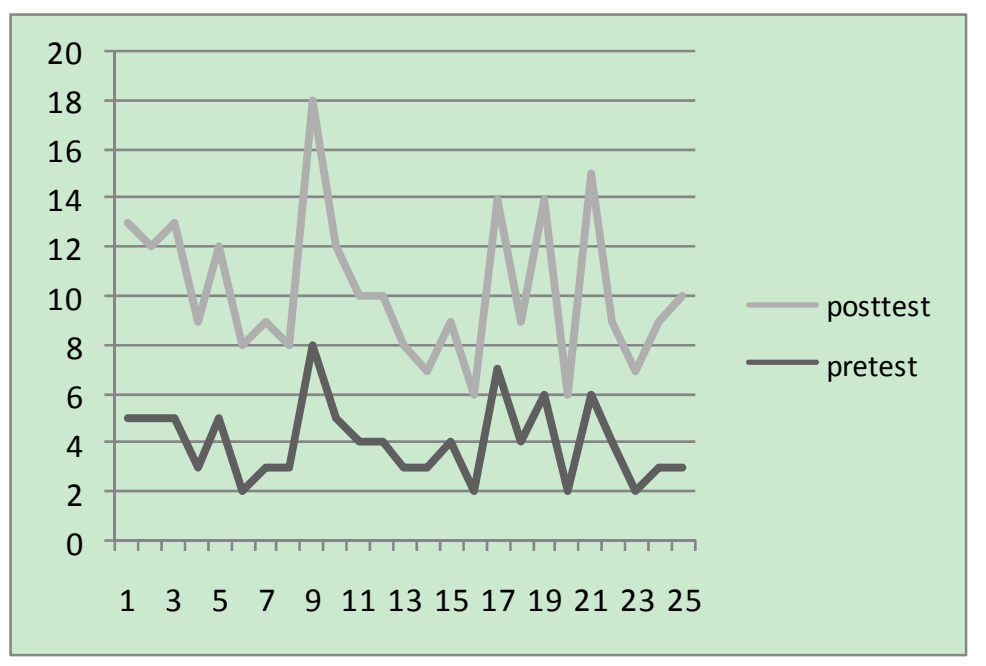

Figure 10. Comparison of geography scores in pretest and posttest (experimental group)

\section{Apendix 1:}

In case you were supposed to study Eng through some reading comprehension texts in one of the following subject matters, which subject would you like most, and which one would you dislike?

\begin{tabular}{|l|l|l|}
\hline & Like & Dislike \\
\hline History & & \\
\hline Sport & & \\
\hline Animal & & \\
\hline Geography & & \\
\hline
\end{tabular}

\section{Apendix 2:}

Which subject of study do you like most?

\section{Apendix 3:}

\begin{tabular}{|l|l|}
\hline Sport & \\
\hline Geography & \\
\hline
\end{tabular}

Geography passage (pretest)

The world we live in is much bigger than what a person can imagine. Our planet has many parts, continents and countries form almost one-third of our planet. We can locate countries and continents, which are separated by each other by their boundaries, in a map. But some maps don't show our planet in details. So, for example, you cannot locate a life-size mountain in them.

Our planet has variety. It consists of different climates in different parts. It also has vegetation. Animal's life, human's life, and vegetation are extremely dependent upon each other. Some of the countries of our planet have coasts which are totally covered by sand. Sometimes, some natural disasters disturb the face of the Earth. Floods ruin all the buildings and jungles, strong thunders almost wipe out everything from the ground, and earthquakes rumble and shake the Earth. This is our planet, with all its beautiful parts, it can be a quite place to live, and meanwhile, it can be extremely dangerous to human beings.

1) The word planet in line one is closest in meaning to-

a- universe

b- surrounding

2) The word boundary in line three is closest in meaning to

a- border

b- fence

3) The phrase life-size mountain in line four is closest in meaning to-

$$
\text { c- world }
$$

d- factory

$$
\begin{array}{lr}
\text { c- } & \text { space } \\
\text { d- } & \text { area }
\end{array}
$$


a- a mountain you have climbed in your life

b- a mountain which is very famous

c- a mountain as high as a real one

d- a small model of a mountain

4) The word variety in line six is closest in meaning to
a- similarity
c- weirdness
b- diversity
d- uniformity

5) The word climate in line six is closest in meaning to
a- region
c- weather
b- mood
d- nature

6) The word vegetation in line seven is closest in meaning to----------------
a- vegetables
c- environment
b- climate
d- plants

7) The word depend on in line seven is closest in meaning to-
a- separate from
c- consist of
b- different from
d- rely on

8) The word coast in line eight is closest in meaning to--------------
a- beach
b- area covered by rocks
c- jungle
d- land

9) The word sand in line eight is closest in meaning to-
a- heavy pieces of stone
c- soil
b- swamp
d- small grains of rocks and minerals

10) The word rumble in line eleven is closest in meaning to
a- make a loud noise
b- happen
c- move
d- destroy the land

Sport passage (pretest)

The spectators have all entered the stadium and taken their seats. The announcer calls out the names of the players together with their numbers, after he has given the primary information both about the stadium where the play is $\underline{\text { held }}$ and the weather. The pre-match procedures still consist of a couple of steps. First of all, the man supervising the game, attends to make sure if the conditions necessary to begin the match are present. The canceling of the match is at the discretion of the supervisor. In the distance, the formerly appointed referees followed by the players enter the pitch in salute. While the host team is welcoming the guest team, the captains go to the referee to toss up a coin and line keepers check the net around the posts of the goal.

1) The word primary in line two is closest in meaning to-------------

$\begin{array}{ll}\text { a- first } & c-\text { basic } \\ \text { b- minor } & \text { d- trivial }\end{array}$

2) The phrase is held in line three is closest in meaning to--------------
a- performed $\quad$ c- was shot

b- started d- took place

3) The word consist of in line four is closest in meaning to--------------

$\begin{array}{ll}\text { a- make use } & \text { c- forbid } \\ \text { b- allow for } & \text { d- include }\end{array}$

4) The word supervise in line four is closest in meaning to---------------
a- enjoy
c- control

b- enter

d- coach

5) The phrase at the discretion of in line six is closest in meaning to-------------
a- caution
c- right to decide
b- emotions and feeling
d- rejection

6) The word distance in line six is closest in meaning to
a- extent
c- range
b- interval
d- field

7) The word appoint in line six is closest in meaning to---------------
a- select
b- exclude
c- ignore
d- prefer

8) The phrase in salute in line seven is closest in meaning to- 
a- with respect c- without respect

b- in the sky d- in the field

9) The word host in line seven is closest in meaning to---------------

a- Rival team c- team that plays outside hometown

b- Team that plays in hometown d- opponent team

10) The word post in line nine is closest in meaning to--------------

a- joint c- bar

b- pole d- line

\section{Treatment}

\section{Sport 1}

A standard adult football match consists of two periods of 45 minutes each, known as halves. Each half runs continuously, meaning that the clock is not stopped when the ball is out of play. There is usually in 15-minute "halftime" break between halves. The end of the match is known as full time.

The referee is the official time keeper for the match, and may make an allowance for time lost through substitutions, injured players requiring attention, or other stoppages. This added time is commonly referred to as stoppage time or injury time, and is at the sole discretion of the referee. The referee alone signals the end of the match. In matches were a fourth official is appointed, toward the end of the half, the referee signals how many minutes of stoppage time he intends to add. The forth official then, informs the players and spectators by holding up a board showing this number. The signaled stoppage time may be further extended by the referee.

Sport 2

Football is played in accordance with a set of rules known as the Laws of the Game. The game is played using a single round ball, known as the football. Two teams of eleven players each compete to get the ball into the other

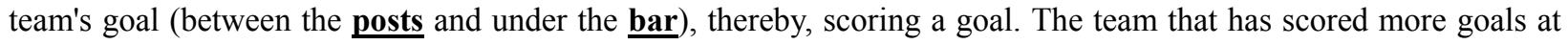
the end of the game is the winner; if both teams have scored an equal number of goals then the game is a draw.

The primary rule is that players (other than goalkeepers) may not deliberately handle the ball with their hands or arms during play. Although players usually use their feet to move the ball around, they may use any part of their bodies other than their hands or arms.

In typical game play, players attempt to create goal scoring opportunities through individual control of the ball, such as by dribbling, passing the ball to a team-mate, and by taking shots at the goal, which is guarded by the opposing goalkeeper.

\section{Sport 3}

The origin or beginning of football may have been a game played by the ancient Greeks called harpastan. In this game, there was no limit to the number of players. The ball was kicked, thrown, or run by the players and the object was to move a ball across a goal by kicking.

The football playing field of today is rectangular in shape and measures 100 yard long and 53.5 yard wide. White lines are painted on the playing field to mark off the distances to the end zone. The game is divided into four quarters, each fifteen minutes long. The first two quarters are known as the first half. There is a rest period between the two halves which usually lasts about fifteen minutes.

Each team has eleven players. Each team has offensive players (play when the team has possession of the ball) and defensive players (play when the other team has possession of the ball). Players are required to wear protective gear to help keep the body safe during the game. Helmets are worn to protect the head and face area. Pads are worn to protect the shoulders, arms and legs. Protective must be worn because of the body contact players have during the game.

Officials supervise the game and are considered to be very important to the game of football. They carry whistles and flags and make certain that the rules of the game are followed during the game.

Sport 4

The Olympic opening ceremony took place in Sydney, Australia on September 15, 2000. It was an international event and the whole world was watching! The event was held in a stadium designed to seat a large group of people.

The athletes entered the stadium in a specific order. The athletes from Greece entered first in honor of the original Olympics held in Greece. Then, the other athletes followed by nation in the alphabetical order of the host country's language. The host country's athletes came last. So, for this Olympics, the athletes from Australia entered the 
stadium last.

The chief of the state of the host country declared the games open, followed by the raising of the Olympics Flag.

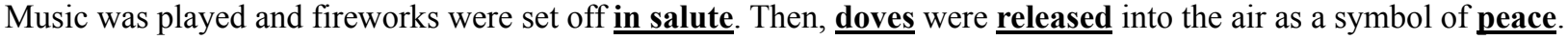

Geography 1

Maps are of the most important tools on Earth. They help us find places. They show us earth's mountains and oceans. To read a map, you need to understand its different parts. Maps are paper diagrams of the Earth's surface. The first part of a map you need to know is its titles. The title tells you what the map is showing. A map of the streets in your town would have your town's name as its title. A compass rose helps you to find direction. Although it is not a flower, it is still important. A simple compass rose may look like a plus sign with arrows. At the ends of arrows the four cardinal directions would be listed. They are north, south, east and west. The top arrow would point to the top of the map, which is north. The bottom arrow points south to the bottom of the map.

The next important part of the map is the symbols. Maps show a smaller picture of the Earth's surface. You can't draw a life-size mountain on a small piece of paper. That is why cartographers use small pictures. Symbols are the points, lines and patterns that are listed in the map key. The key is a box located in one the bottom corners of the map. Symbols have different colors depending on the physical feature the drawing represents. For example, water features like rivers, lakes, and oceans are colored blue. Trees, woods, orchards and shrubs are usually colored green. Red is used for important roads. What about buildings and mountains? Well, buildings are colored black, the mountains and hills are colored blue.

Geography 2

Our planet has many places. Most of these places are filled with people. Can you imagine all of the houses, schools, and stores that are on Earth? Geographers do! They study how we use the land that is found on Earth. What have they learned? Geographers have found out that we divide our continents into smaller areas. These areas are called countries, states, towns, and cities.

Countries or nations are large pieces of land that have boundaries. On a political map we see these boundaries. They outline the areas that belong to each country. These boundaries are also made by us. Governments or the people who make laws decide where the boundaries should be for their country.

Countries are divided into smaller areas. The U.S.A. is divided into fifty states. States are areas that have their own government. They are outlined by boundaries. States have their own set of laws. They must also follow the laws of the U.S.A. Two of American states, Alaska and Hawaii, do not touch the other forty-eight states. Canada is between Alaska and the states on the west coast. The state boundaries are usually thinner than country boundaries.

Geography 3

Our rotating sphere changes every day. Its physical features change when volcanoes erupt and earthquakes rumble. People remove trees and soil to add new buildings and structures. Geographers need to learn about these changes. They also need to learn about changes in Earth's past.

Earth is extremely large. Studying its features can be overwhelming. So, to make it easier, geographers divide the earth into regions. Regions are areas that share common features. These features can be landforms, climate, economy, vegetation or people. The states or countries within these regions are also located in the same area. Geographers create these regions based on the information they want to study.

\section{Geography 4}

The view of Earth from space must be very interesting. Imagine seeing the different colors, shapes and structures on our planet. Well, thanks to nature, Earth has variety! It has geographical landforms.

Landforms are physical features on Earth that are made by nature. These features are seen on maps and on globes. Landforms can be classified into two categories: land and water. We will start with water.

You know that oceans are bodies of salt water. Well, seas also contain salt water. However, they are smaller than oceans. Seas also empty into some of our oceans. Gulfs are found inland or towards the land. They are part of the sea or ocean. The Gulf of Mexico is found near the southern coast of the United States. Rivers, lakes and $\underline{\mathbf{s t r e a m s}}$, as you know, empty into seas, gulfs and oceans. Lakes are bodies of water that are surrounded by land.

Coasts are the land that is near a sea or ocean. Two of the coastlines in the U.S. are the Pacific Coast and Atlantic Coast. The Pacific Ocean borders the U.S in the west and the Atlantic Ocean is its eastern border. Deltas are also found near coastlines. Deltas are areas of mud and sand that form at river mouth. This is where the mud and sand settle at the end of a river. The speed of the river slows down as it meets the larger body of water. 


\section{Geography passage (posttest)}

Most of the time people know about the area they live in, but the moment they step out of the known boundary, they encounter variety of climates as well as diversity of vegetation, as if they traveled to another planet. Even if they travelers read about the destination of their journey, the element of surprise would totally depend on how different the experience might be from what they went through in their own countries. As tangible examples, a life-size volcano that rumbles or a land which is covered by sand along the coastline of the ocean is things one may extremely be afraid of or die for. That is why tourists will never be satisfied by visiting different countries.

1) The word boundary in line two is closest in meaning to-
a- border
b- house
c- space
d- barrier

2) The word variety in line two is closest in meaning to--
a- oddness
c- diversity
b- exactness
d- similarity

3) The word climate in line two is closest in meaning to--
a- situation
c- place
b- weather
d- animate

4) The word vegetation in line two is closest in meaning to
a- animals
b- human beings
c- vegetables
d- plants

5) The word planet in line three is closest in meaning to------------

a- a small round object in the space

b- a large round object in the space

c- a small shiny object in the space

d- a big shiny object in the space

6) The word depend on in line four is closest in meaning to
a- bring about
c- rely on
b- set aside
d- allow for

7) The phrase life-size volcano in line five is closest in meaning to-

a- a volcano which is shown on a map

b- a volcano which is activated

c- a volcano which is as big as a real one

d- a small model of volcano

8) The word rumble in line six is closest in meaning to-
a- produce lava
c- roar
b- make soft sound
d- make a whispering sound

9) The word sand in line six is closest in meaning to------------
a- shore
b- small grains of rocks and minerals
c- mud
d- big pieces of stone

10) The word coastline in line six is closest in meaning to
a- sand around a swamp
b- desert
c- a line drawn near the sea
d- shoreline

Sport passage (posttest)

One of the most interesting and exciting sports played in northern countries of Europe, is skiing. Every four year a competition is held in countries like Switzerland, Sweden or Germany and athletes come together at the host country to take part in this competition. The tools used in this sport consist of two long poles and two skis. In the field which is totally covered by snow, many posts are fit in the ground. The referees who are appointed by the Ski Association are introduced in beginning of the ceremony in salute. The primary goal for the athletes is to pass a certain distance, by moving in between the posts in the shortest time possible. The movement of the athletes is supervised at the discretion of the referees. Then, the referees keep record of the time beaten by each athlete, and the one with the shortest time becomes the champion of the competition.

1) The phrase is held in line two is closest in meaning to 

a- take place
c- is canceled
b- begins
$\mathrm{d}-$ is televised

2) The word host in line three is closest in meaning to
a- a team that plays outside
c- presenter
b- announcer
d- a team that plays at home

3) The word consist of in line four is closest in meaning to
a- combine
c- determine
b- include
d- exclude

4) The word post in line five is closest in meaning to-
a- bar
c- pole
b- line
d- corner

5) The word appointed in line five is closest in meaning
a- trained
c- selected
b- encouraged
d- ignored

6) The word in salute in line six is closest in meaning to
a- in respect
c- in solitude
b- without respect
d- in groups

7) The word primary in line six is closest in meaning to
a- last
c- trivial
b- first
d- proper

8) The word distance in line seven is closest in meaning to
a- short time
c- entrance
b- extent
d- field

9) The word supervised in line eight is closest in meaning to
a- ignored
c- handled
b- amused
d- controlled

10) The word discretion in line eight is closest in meaning to

a- the mood

b- the sight c- the right

d- the interest 